\title{
A Phage P22 Gene Controlling Integration of Prophage'
}

\author{
HAMILTON O. SMITH AND MYRON LEVINE \\ Department of Human Genetics, and the Lawrence D. Buhl Research Center for Human Genetics, \\ University of Michigan, Ann Arbor, Michigan \\ Accepled Oclober 11, 1966
}

\begin{abstract}
A mutnally noncomplementing group of phage P22 mutants ( $L$ mutants) have been isolated which cannot accomplish a late step necessary for prophage integration. $L$ mutants produce turbid plaques and lead to cell survival on high multiplicity infection, but the infecting phage genomes are incapable of intcgrating as prophage and are progressively diluted among the segregating cells. $L$ mutants can become prophage by complementation with $L^{+}$phage. The $L^{+}$gene apparently produces a diffusible product which acts trans to accomplish inlegration. Experiments with temperature sensitive $L$ mutants show that the gene begins acting late, after the infected cells have recovered and begun to divide, and does not accomplish its effect in all the cells until at least the third generation. $L$ lysogens formed by complementation are stable. The $L^{+}$gene is thus necessary for integration but not for maintenance of the lysogenic state.
\end{abstract}

\section{INTRODUCTION}

According to the model proposed by Campbell (1962) for prophage integration, intracellular phage DNA enters a circular form after infection. A region of the circular genome then aligns with a homologous region on the bacterial genome, and the phage DNA is inserted into the host chromosome by a process similar to recombination. A considerable amount of evidence now supports this theory. Circular forms of intracellular phage DNA have been found for both $\lambda$ and P22 phage (Young and Sinsheimer, 1964; Bode and Kaiser, 1965; Rhoades, personal communication). Prophage is inserted into the continuity of the host chromosome (Franklin et al., 1965) in a specifically altered gene order which is a circular permutation of the vegetative order (Calef and Licciardello, 1960; Rothman, 1965; Smith and Levine, 1965b). The site of insertion on the bacterial chromosome is very specific; phage $\lambda$ inserts on the Escherichia coli chromosome between the galactose operon and biotin (Rothman, 1965); phage P22 inserts on the Salmonella typhimurium

1 This work was supported by U.S. Public Health Service Grant GM-09252-04. chromosome between the proline $A$ and $C$ cistrons (Smith and Levine, 1965b; Smith, unpublished). Actual DNA homology detween the phage and bacterial sites of attachment has not yet been rigorously shown, although it seems very likely.

It is reasonable to assume that phage genes control some of the steps involved in prophage integration. Phage mutants blocked in ability to carry out a necessary step would be incapable of integration. Such mutants on infection, should behave in a way similar to the $b_{2}$ deletion mutant of phage $\lambda$. This mutant is deleted in the phage attachment region and cannot integrate as prophage. Infected cells survive and carry the $\lambda b_{2}$ phage genomes, but the genomes do not integrate or replicate and are progressively diluted among the progeny cells as growth of the culture proceeds (Zichichi and Kellenberger, 1963).

A search was undertaken for phage P22 mutants behaving similarly to $\lambda b_{2}$ on infection. A number of such mutants were isolated. These belong to a single complementation group, and they appear to be point mutants which affect a late function necessary for integration of prophage. 


\section{MATERIAIS AND METHODS}

Phage and bacterial strains. Mutant phage stocks were derived from wild-type phage P22. Phage mutants containing plaque morphology markers $m_{3}, c_{2}$, and $h_{21}$ have been described previously (Levine and Curtiss, 1961). Experiments were performed with Salmonella typhimurium LT2. Lysogens were prepared on a strain of $1 \mathrm{~T} 2$ cured for phage B of Boyd, originally isolated by Zinder (1958). A gal- strain was used as plating bacteria.

Media. The media used (see Levine, 1957) were as follows: Broth (Bacto-tryptone $10 \mathrm{~g}, \mathrm{NaCl} 10 \mathrm{~g}$, yeast extract ǰ g, glucose $1 \mathrm{~g}$, distilled water $1000 \mathrm{ml}$, adjusted to pH 7). Nutrient agar (Difco nutrient broth powder $8 \mathrm{~g}, \mathrm{NaCl} 5 \mathrm{~g}$, Difco bacto agar $15 \mathrm{~g}$, distilled water $1000 \mathrm{ml}, \mathrm{pH}$ 7). EMB-galactose agar (Bacto-tryptone $8 \mathrm{~g}$, yeast extract $1 \mathrm{~g}, \mathrm{NaCl} 5 \mathrm{~g}$, Bacto agar $15 \mathrm{~g}$, distilled water $900 \mathrm{ml}$; autoclave and add $2 \%$ eosin $20 \mathrm{ml}, 0.5 \%$ methylene blue $13 \mathrm{ml}, 16 \%$ $\mathrm{K}_{2} \mathrm{HPO}_{4} 12 \mathrm{ml}, 30 \%$ galactose $30 \mathrm{ml}$ ). Indicator agar (Bacto-tryptone $8 \mathrm{~g}$, yeast extract $1 \mathrm{~g}, \mathrm{NaCl} 5 \mathrm{~g}$, bacto agar $15 \mathrm{~g}$, distilled water $1000 \mathrm{ml}$; autoclave and add $2.5 \%$ alizarin yellow $25 \mathrm{ml}, 2 \%$ soluble blue 3.3 $\mathrm{ml}, 40 \%$ glucose $21 \mathrm{ml}$ ).

Selection of mutants. The behavior of phage mutants not able to produce stable lysogens could be inferred from observations already noted with certain pro $A$ deletion mutants of $S$. typhimurium. These apparently also lacked the site for prophage attachment (Smith and Levine, 1965b) and were unable to form stable lysogens following infection with wild-type phage P22, a situation analogous to, but reciprocal to, that of the $\lambda b_{2}$ mutant. Infecting phage genomes were rapidly diluted out of growing cultures, and the infected cells became sensitive. Although the pro $A$ deletion mutants cannot be lysogenized, wild-lype phage plate on these and give a normal turbid-plaque morphology. An empirical spot test was developed to distinguish between this unstable state and infections leading to stable lysogenization. Cells from the center of turbid plaques were picked on a sterile needle and spotted on indicator agar and incubated for colony formation. Colonies derived from the center of plaques of wild-type phage plated on wild-type cells are large and light green. This will be called the wild-type response. In contrast, cells from plaques of wild-type phage plated on pro $A$ deletion mutants produce small dark colonies. This is termed the unstable response.

A probable explanation for the differences in colony morphology is as follows: Cells from the center of plaques plated on the deletion mutants do not contain integrated prophage, and consequently many sensitive cells are segregated as growth proceeds. These sensitive cells can be reinfected and lysed, causing the colony to grow more slowly. Cells undergoing lysis produce an increased dye reaction on the indicator agar, hence the darker color. On the other hand, stably lysogenized cells are formed in plaques on a wild-type background. These are immune to reinfection and produce a larger colony without the dye reaction characteristic of cell lysis.

Phage mutants were selected for the two characteristics: (1) wild-type plaque morphology, and (2) the unstable response when cells from the center of plaques on standard plating bacteria are spotted on indicator agar and incubated at $37^{\circ}$.

Mutagenesis of wild-type phage was carried out as follows: One milliliter of $\log$ phase cells at a concentration of $10^{8}$ cells $/ \mathrm{ml}$ was infected in broth at $37^{\circ}$ with $10^{8}$ wildtype phage. Five minutes was allowed for adsorption; unadsorbed phage were then inactivated by addition of antiphage serum. The infected cells were diluted to $10^{4}$ cells / $\mathrm{ml}$ in broth containing $4 \mu \mathrm{g} / \mathrm{mI} N$-methyl- $N^{\prime}$ nitro- $N$-nitrosoguanidine and distributed into $401-\mathrm{ml}$ aliquots. After 60 minutes' incubation, the lysates were treated with chloroform. Mutagen-treated phage from each tube were plated on nutrient agar. The level of mutation was high as shown by the $5 \%$ incidence of clear plaques. Morphologically wild-type plaques were tested for the unstable response at $37^{\circ}$. Approximately $3 \%$ gave the small green colony on indicator agar characteristic of unstable lysogeny. Phage was recovered from these colonies by a single plaque isolation. A single mutant, was derived from each of the original independently mutagen-treated lysales. These were designated $L 1-L, 40$. 
Phage infections and detection of phagecarrying cells. Infections were carried out in broth on $\log$ phase cells. Cells were grown at $37^{\circ}$ to a concentration of $10^{8}$ cells $/ \mathrm{ml}$ and infected in all cases with a multiplicity of 20 phage particles. Further details for each experiment are given under results.

Phage-carrying cells are defined as cells capable of producing phage (Zinder, 1958). In such phage carriers, intracellular phage genomes may exist free or as integrated prophage. A carrier may be detected either by spontaneous release of phage from the cell or its descendants (Zinder, 1958), or by an inducing treatment to produce infective centers (Zichichi and Kiellenberger, 1963). We have chosen the former procedure. Cells to be tested were plated by the soft-agaroverlay method with a background of gatcells on FMB-galactose plates. Plates were incubated for 48-60 hours at room temperature. Phage-carrying cells gave rise to colonies with a surrounding halo of lysis due to spontaneous phage release, whereas nonphage-carrying (sensitive) cells produced no halo (Levine, 1957).

Complementation test. Cells were infected with a multiplicity of 10 particles of each of the two mutants to be tested. The infected cells were spread over the surface of indicator agar and incubated overnight at $37^{\circ}$. If the majority of colonies gave a wildtype response indicating presence of stable lysogeny, then the two mutants were considered to be complementary. If all the colonies yielded an unstable response then the two mutants were scored as noncomplementary.

\section{RESULTS}

Complementation Testing and Isolation of $L$ mutant Lysogens

All the $L$ mutants fail to complement with L1, with the single exception of L21 (Table 1). The 39 mutants thus comprise a single complementation group or gene affecting the ability to lysogenize. The exceptional mutant, L21, although fitting the original selection criteria of wild-type plaque morphology and an unstable response on indicator agar, is for several reasons not in the same group and will not be discussed further in this report.

Mixed infection of an $L$ mutant with a
TABLE 1

Summary of L-Mutant Properties

\begin{tabular}{|c|c|c|c|c|c|}
\hline \multirow[t]{2}{*}{$\begin{array}{c}L \text { Mutant } \\
\text { number }\end{array}$} & \multicolumn{2}{|c|}{$\begin{array}{l}\text { Complemen- } \\
\text { tation with }\end{array}$} & \multicolumn{2}{|c|}{$\begin{array}{l}\text { Percentage } \\
\text { integration } \\
\text { efficiency }^{a}\end{array}$} & \multirow{2}{*}{$\begin{array}{l}\text { Yield of infective } \\
\text { particles per UV- } \\
\text { induced cell rela- } \\
\text { tive to wild } \\
\text { type at } 37^{\circ}\end{array}$} \\
\hline & $L I$ & $v_{1} c_{2}$ & $25^{\circ}$ & $37^{\circ}$ & \\
\hline 1 & 0 & + & 70 & $<0.25$ & 0.37 \\
\hline 2 & 0 & + & & & 0.00022 \\
\hline 3 & 0 & + & & & 0.00033 \\
\hline 4 & 0 & + & & & 10.0 \\
\hline 5 & 0 & + & & & 0.00052 \\
\hline 6 & 0 & + & & & 0.22 \\
\hline 7 & 0 & + & & & 0.0095 \\
\hline 8 & 0 & + & & & - \\
\hline 9 & 0 & + & & & 0.0037 \\
\hline 10 & 0 & + & 72 & $<3.2$ & 0.055 \\
\hline 11 & 0 & + & & & 0.00024 \\
\hline 12 & 0 & + & 49 & $<1.1$ & 0.048 \\
\hline 13 & 0 & + & & & 0.0013 \\
\hline 14 & 0 & + & & & 0.070 \\
\hline 15 & 0 & + & & & 0.11 \\
\hline 16 & 0 & + & 42 & $<1.5$ & 0.16 \\
\hline 17 & 0 & + & & & 0.00085 \\
\hline 18 & 0 & + & & & 0.00020 \\
\hline 19 & 0 & + & & & 0.0022 \\
\hline 20 & 0 & + & & & 0.039 \\
\hline 21 & + & $?$ & & & - \\
\hline 22 & 0 & + & & & 0.043 \\
\hline 23 & 0 & + & & & 0.0022 \\
\hline 24 & 0 & + & & & 0.0047 \\
\hline 25 & 0 & + & 54 & $<1.0$ & 0.0032 \\
\hline 26 & 0 & + & & & 0.0066 \\
\hline 27 & 0 & + & & & 0.00097 \\
\hline 28 & 0 & + & & & 0.057 \\
\hline 29 & 0 & + & & & 0.41 \\
\hline 30 & 0 & + & & & 0.00017 \\
\hline 31 & 0 & + & & & 0.0026 \\
\hline 32 & 0 & + & & & 0.00031 \\
\hline 33 & 0 & + & & & 0.16 \\
\hline 34 & 0 & + & & & 0.0057 \\
\hline 35 & 0 & + & & & 0.12 \\
\hline 36 & 0 & + & 58 & $<2.2$ & 0.24 \\
\hline 37 & 0 & + & & & 0.64 \\
\hline 38 & 0 & + & 71 & $<1.5$ & 0.056 \\
\hline 39 & 0 & + & & & 0.015 \\
\hline 40 & 0 & + & & & 0.0019 \\
\hline Wild & + & + & 90 & 30 & 1.00 \\
\hline
\end{tabular}

antegration efficiencies are given only for the temperature-sensitive $L$ mutants. All other mutants show essentially zero integration efficiencies at either temperature. 
TABLE 2

Localization of Selected $L$ Mutants with Respect to Morphological Markers $m_{3}, c_{2}$, and $h_{21}$ By Genetrc Crosses

\begin{tabular}{lrrrrrrrc}
\hline \multirow{2}{*}{ Crosses } & \multicolumn{3}{c}{ Single crossover classes examined } & & \multicolumn{3}{c}{ Relative distance $^{a}$} \\
\cline { 2 - 4 } \cline { 7 - 8 } & $m_{3} L+$ & $m_{3}++$ & $+L h_{21}$ & $++h_{21}$ & & $m_{3}-L$ & $L-c_{2}$ & $L-h_{21}$ \\
\hline$L 1 \times m_{3} h_{21}$ & 107 & 112 & 85 & 76 & 0.48 & - & 0.52 \\
$L 1 \times m_{3} c_{2}$ & 61 & 30 & - & - & 0.67 & 0.33 & - \\
$L 7 \times m_{3} c_{2}$ & 115 & 26 & - & - & 0.81 & 0.19 & - \\
$L 14 \times m_{3} c_{2}$ & 127 & 37 & - & - & 0.77 & 0.23 & - \\
$L 15 \times m_{3} c_{2}$ & 127 & 50 & - & - & 0.72 & 0.28 & - \\
\hline
\end{tabular}

${ }^{a}$ Relative distance from $L$ to each morphological marker was approximated from the single crossover data; e.g., distance $L-c_{2}=$ number of $m_{3}++$ recombinants/(number of $m_{3} L+$ recombinants + number of $m_{3}++$ resombinants).

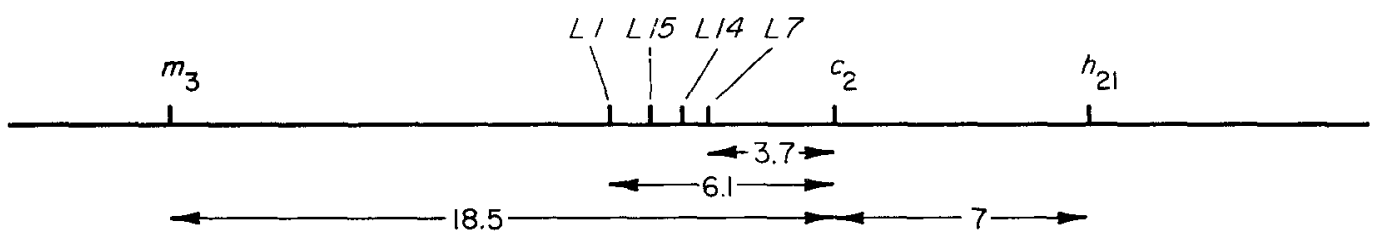

Fig. 1. Map positions of several $L$ mutants in relation to the morphological markers $m_{3}, c_{2}$, and $h_{21}$ (see Table 2). The linkage relations for the morphological markers are from Levine and Curtiss (1961).

nonlysogenizing double mutant, $v_{1} c_{2}$ (Zinder, 1958; Levine, 1957), resulted in complementation (Table 1). Lysogens carrying the $L$-mutant genome as a stable prophage could easily be isolated from the mixed infections. The existence of stable lysogens for the $L$ mutants indicates that this gene is concerned not with maintenance of lysogeny, but with some step in the establishment of the lysogenic state. Once this step is accomplished and the prophage state is reached, the function is no longer needed.

Lysogens for each of the $L$ mutants were isolated by complementation. It was noted in preliminary tests of stability of these lysogens that the spontaneous release of infective phage was very low. Consequently, the phage yield from ultraviolet light-induced cells was checked and found also to be low for nearly all the lysogens (Table 1, last column). In many cases, the yield of infective particles was $10^{-3}$ to $10^{-4}$ below that of a wild-type lysogen similarly induced. Preliminary studies of this effect have revealed that induced $L$ lysogens release essentially normal numbers of particles as assayed by O.D. 260 when banded in a $\mathrm{CsCl}$ density gradient, but these are defective and cannot be detected as infectious particles. The nature of this effect and a characterization of the defective particles is under study and will be presented in a later publication.

\section{Genetic Mapping of the L Mutants}

The absence of a distinguishable plaque morphology prevented detailed mapping of the $L$ mutants. However, $L$-mutant plaques could be identified by the unstable response obtained when spotted onto indicator agar. An attempt was made to localize several $L$ mutants with respect to the morphological markers $m_{3}, c_{2}$, and $h_{21}$. The crosses indicated in Table 2 were performed using a multiplicity of 10 phage of each parental type. Morphological recombinants from each cross were scored for presence or absence of the $L$ phenotype. In $L \times m_{3} c_{2}$ crosses only turbid $m_{3}+$ recombinants were scored for $L$; the $+c_{2}$ recombinants formed clear plaques which could not be tested for $L$. The relative position of $L$ with respect to $m_{3}$ and $c_{2}$ was calculated from the proportion of $m_{3} L+$ and $m_{3}++$ recombinants (Table 2), predominance of $m_{3} L+$ indicating closer linkage to $c_{2}$. Approximate map positions are shown in Fig. 1. 

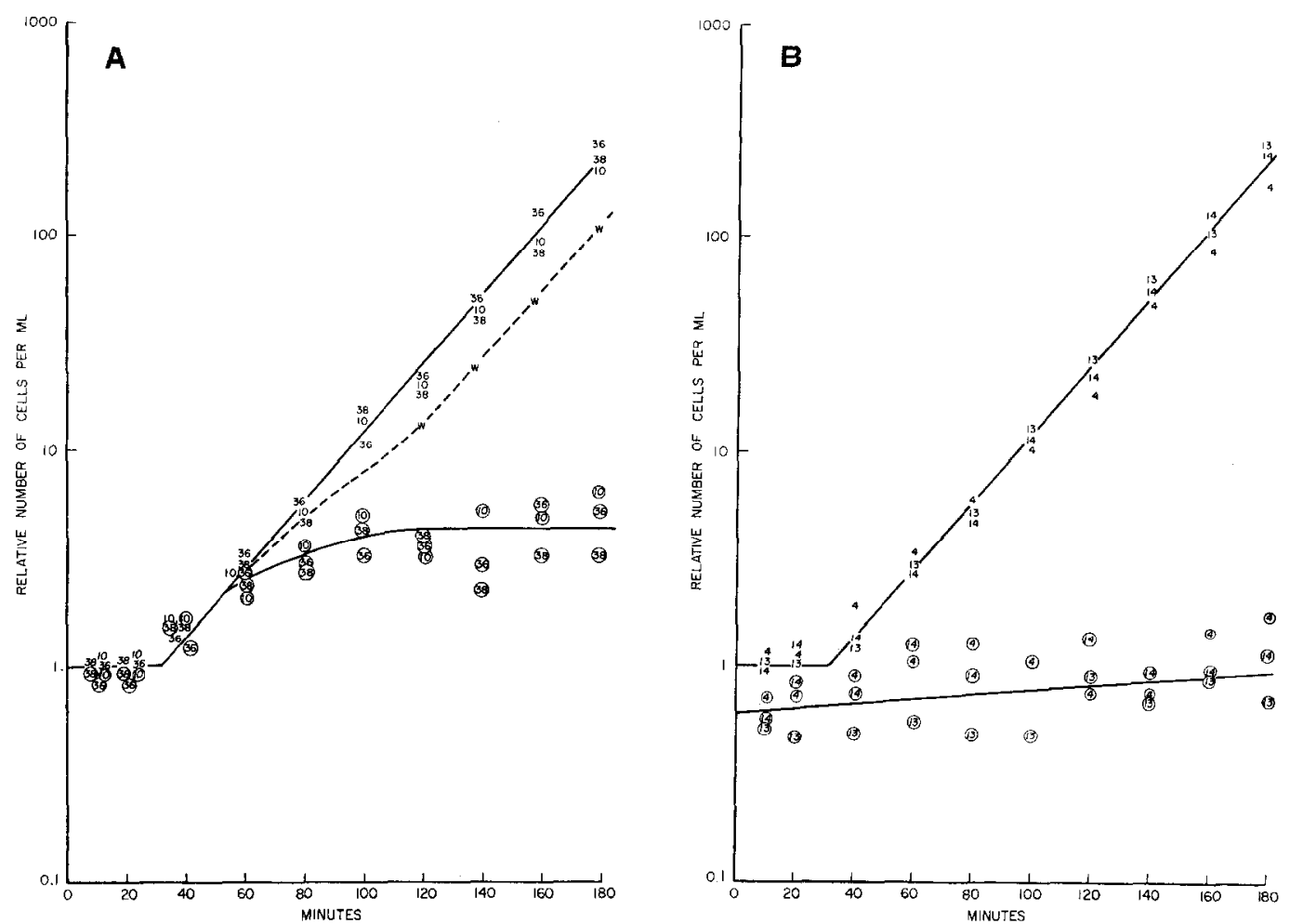

FIg. 2. Segregation of phage-carrying and sensitive cells at $37^{\circ}$ following infection with a multiplicity of 20 particles. Cell numbers are relative to the initial number of infected cells. Total cells are represented by numbers corresponding to the $L$. mutants used in the infection. The numbers enclosed in circles represent the number of phage-carrying cells. (A) Segregation of temperature-sensitive mutants $L 10, L 36, L 38$. The dashed line represents, for comparison, phage carriers in a wild-type phage infection. Total cells in the wild-type infection were the same as for the other infections. (B) Similar data are shown for nontemperature-sensitive mutants $L 4, L 13, L 14$.

\section{Temperature-Sensitive L Mutants.}

Mutants were originally selected for production of the unstable response at $37^{\circ}$. Most of the mutants also gave the unstable response at $25^{\circ}$. However, seven mutants, $L 1$, $10,12,16,25,36$, and 38 , were temperature sensitive by spot testing. They produced the characteristic unstable response at $37^{\circ}$ but gave the wild-type response at $25^{\circ}$. In the next section additional confirmation of temperature sensitivity for these mutants is given.

Segregation Pattern of Cells Infected with $L$ Mutants.

To determine the intracellular fate of the $L$-mutant phage genomes, a study of the segregation pattern of infected cells was undertaken. Log phase cells were infected with a multiplicity of 20 phage particles.
After a 5-minute adsorption period, the cells were diluted to $10^{3}$ cells $/ \mathrm{ml}$ in broth containing antiphage serum $(K=2.8)$. At intervals, aliquots were plated on EMBgalactose agar for determination of the frequency of sensitive cells, phage-carrying cells, and total cells.

In the control infection at $37^{\circ}$, using wildtype phage, a high proportion of the cells $(95 \%)$ survived as phage carriers. These began dividing after a lag of about one gencration, and thereafter the total number of cells increased logarithmically. The proportion of phage carriers to total cells remained high for the first few divisions, but eventually about half the cells segregated as sensitives and half persisted as lysogens. The ratio of phage carriers to total cells remained constant at approximately $50 \%$ after the fifth generation (Fig. 2A). 
Infection with $L$ mutant phage at $37^{\circ}$ gave two patterns of segregation depending on whether the mutants were temperature sensitive or not (Fig. $2 \mathrm{~A}$ and $\mathrm{B}$ ). In the initial stages, as with wild-type infection, a high proportion of the cells survived as phage carriers, but the number of phage carriers either increased approximately 5fold and then remained constant (Fig. 2A, temperature-sensitive mutants), or did not increase at all (Fig. 2B, non-temperaturesensitive mutants). In both cases the ratio of phage carriers to total cells continued to decrease with each division. It may be conrluded that in the control infection, after an early period of segregation of intracellular phage genomes, prophage integration has occurred because the capacity to produce phage is perpetuated synchronously with cell growth, whereas, in the $I$ mutant infections, the number of phage-carrying cells becomes constant, indicating absence of stable lysogeny (compare Zichichi and Kellenberger, 1963).

The absence of an increase in phage carriers during the initial divisions with non-temperature-sensitive $L$ mutants is probably an artifact due to inadequate detection of phage carriers on EMB-galactose plates. Only one or a few cells in the colony contain phage since there is no integration. The probability of these releasing phage during the 48-60 hour room temperature incubation is apparently low. The results could be explained if this probability were $0.1-0.05$. With temperature-sensitive $L$ mutants the increase is observed because phage integrates when the plates are incubated at room temperature. When, for one of the non-temperature-sensitive $L$ mutants, phage-carriers were detected by an induction treatment to produce infective centers, results similar to those of Fig. 2A were obtained.

Segregation curves have proved useful for quantitating prophage integration. We can define a value, called integration effciency, as the ratio of phage carriers to total cells after a large number of generations. More precisely, integration efficiency, $I$, is defined as $\left(f_{\infty} / f_{0}\right) \times 100$ where $f_{0}$ and $f_{\infty}$ are the percentage of phage carriers initially and after many generations, respectively. Only cells nitially containing phage are thus consid-

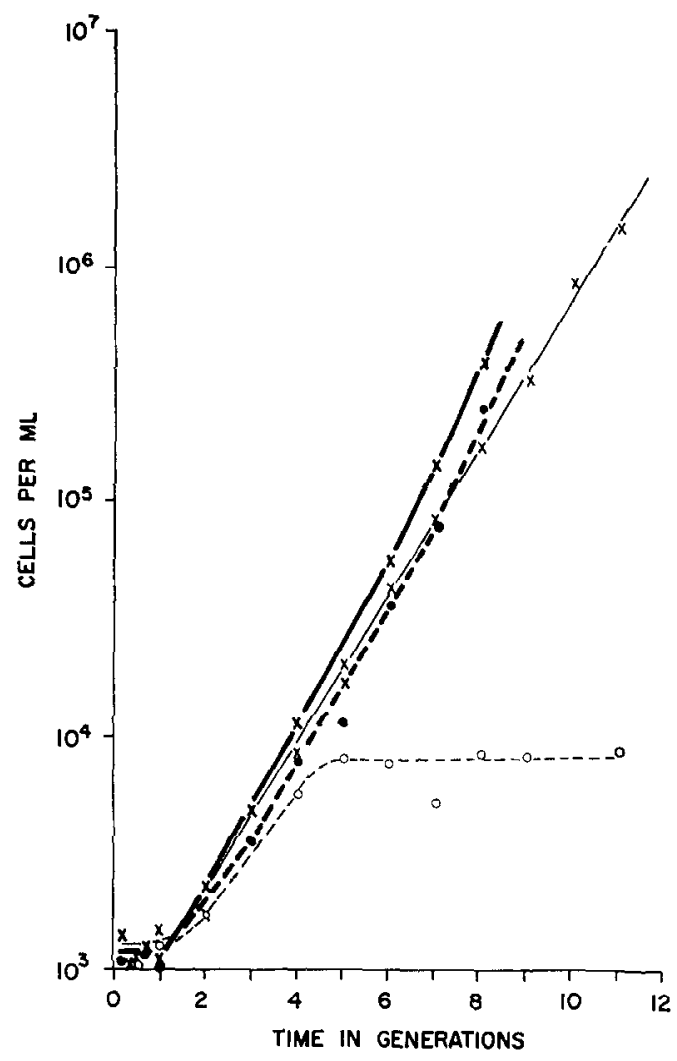

Fig. 3. Segregation pattern of temperaturesensitive $L 1$ infected cells at $25^{\circ}$ and $37^{\circ}$. Total cells, $X-X$, and phage carriers, ---- at $25^{\circ}$. Total cells, $X \longrightarrow X$, and phage carriers, $0-\cdots$, at $37^{\circ}$. The time scale is in generations to simplify comparison of data at the two temperatures (generation time equals 20 minutes at $37^{\circ}$ and 60 minutes at $25^{\circ}$ ).

ered, as these are the only ones having genomes which are exposed to possible integration. Generally the percentage of phage carriers reaches a constant value after 5-7 generations. Arbitrarily 8 or more generations of growth were considered sufficient for determination of $f_{\infty}$.

Reference to Fig. 2 shows integration efficiencies of less than $1-2 \%$ for several $L$ mutants. The actual efficiencies are probably nearly zero, but it is not practical to follow growth for longer periods.

Integration efficiencies were measured at $25^{\circ}$ and at $37^{\circ}$ for the mutants classified as temperature sensitive by spot testing. Each of the seven mutants produced very low integration efficiencies at $37^{\circ}$ but gave values of $40-70 \%$ at $25^{\circ}$ (Table 1 , columns 4 and 


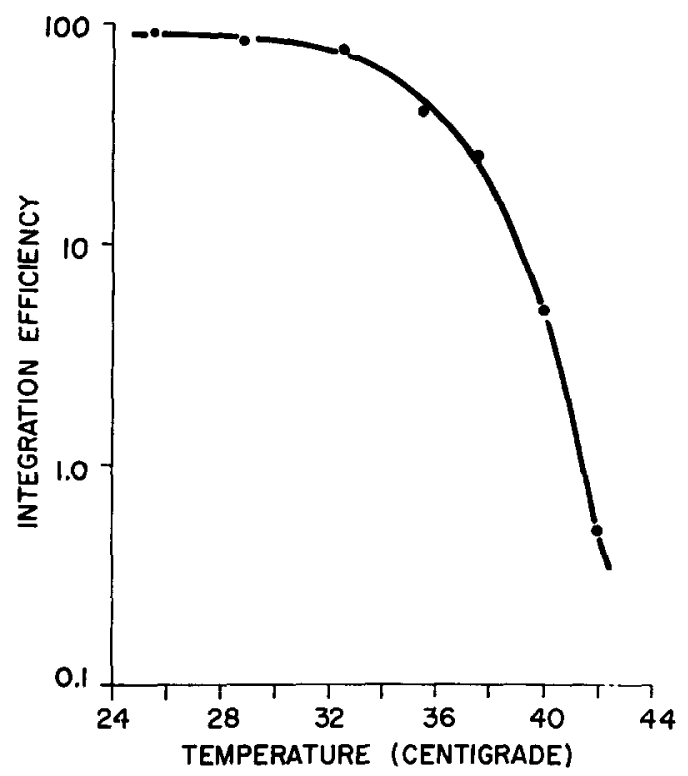

FIG. 4. Integration efficiencies for wild-type phage as a function of temperature. At each temperature cells infected with a multiplicity of 20 phage were allowed to segregate for 8 to 9 generations. The final percentage of phage carriers relative to total cells is plotted against the temperature.
5). Complete segregation patterns for the temperature-sensitive mutant $L 1$ at $25^{\circ}$ and $37^{\circ}$ are shown in Fig. 3. The segregation pattern at $25^{\circ}$ is very similar to that for wild-type (Fig. 2A), and at $37^{\circ}$ the pattern is typical of the $L$ phenotype. The other temperature sensitive $L$ mutants behaved similarly to $L 1$ at the two temperatures.

Of interest is the finding that integration efficiency for wild-type phage varies markedly with temperature, exceeding $90 \%$ at $25^{\circ}$ and dropping to less than $1 \%$ at $42^{\circ}$ (Fig. 4). Wild-type phage thus behaves phenotypically like a weak temperature-sensitive $L$ mutant. Inability to find any additional locus among forty nonintegrating mutants makes it likely that the behavior of wildtype phage is actually due to the $L$ locus. The effect of temperature on lysogenization of wild-type phage has been previously noted for phage P22 (Luria et al., 1957) and for phage $\lambda$ (Lieb, $1953 \mathrm{a}$ ).

\section{Temperature-Shift Experiments}

An accurate measure of the time course of temperature sensitivity of $L 1$ function

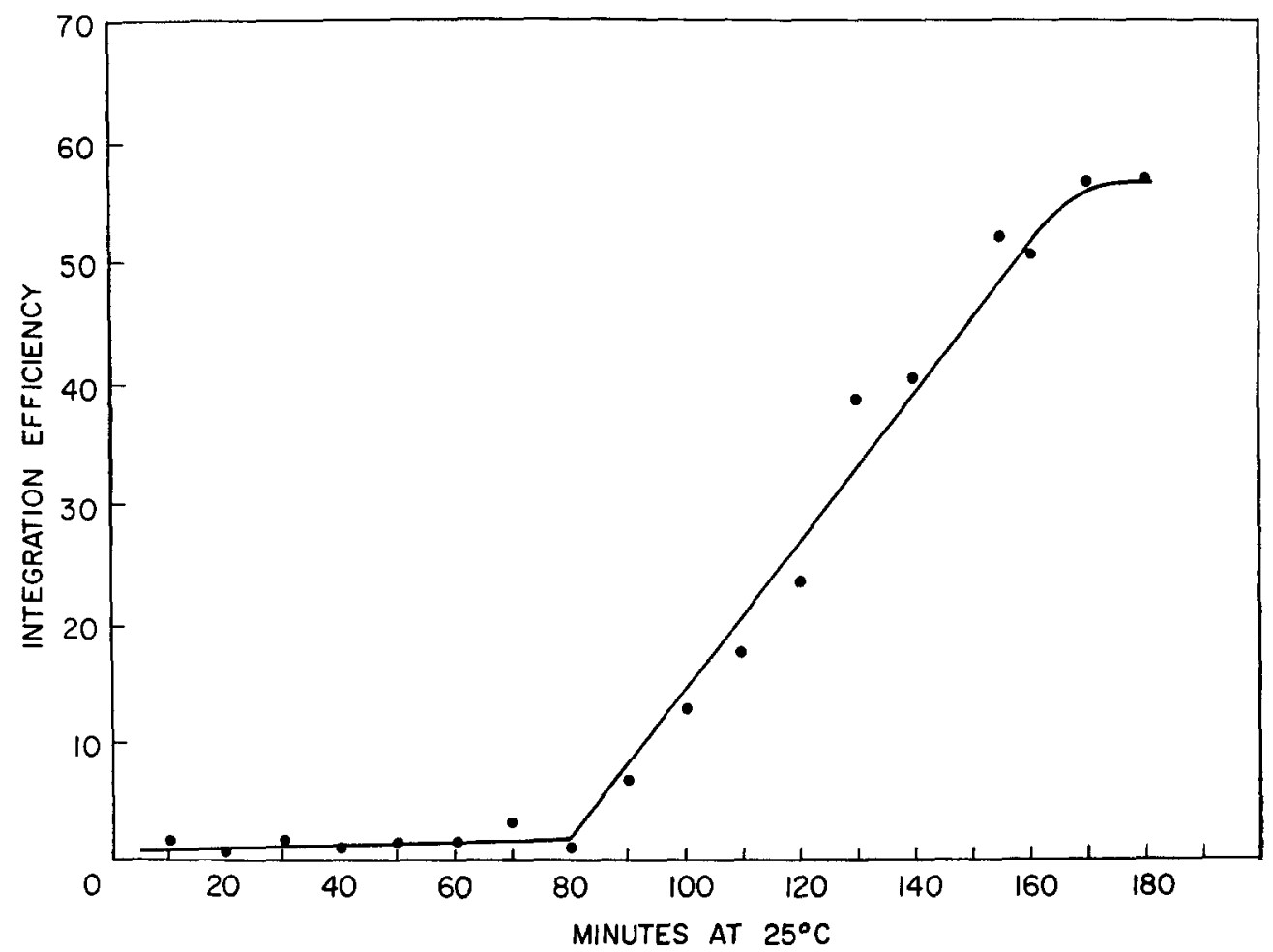

FIG. 5. Integration efficiency of $L 1$ phage as a function of the time infected cells spend at $25^{\circ}$ prior to transfer to $37^{\circ}$. 
was obtained by measuring integration efficiency after various lengths of exposure to $25^{\circ}$. Infected cells were diluted to $10^{3}$ cells/ $\mathrm{ml}$ in broth at $25^{\circ}$ containing antiphage serum $(K=2.8)$. One-milliliter aliquots were removed to $37^{\circ}$ at 10 -minute intervals and incubated for 3 hours ( 9 generations), allowing lysogenic cells to reach a constant percentage of total cells. The rationale for the experiment may be stated as follows: The $37^{\circ}$ segregation served simply as a test for the amount of integration which had occurred, or had been made possible by some elaborated product, during the preceding period of $25^{\circ}$ incubation. No further integration, or at least no further production of necessary product, was possible after transfer to $37^{\circ}$.

No significant integration of prophage was detected during the first 80 minutes of infection. Thereafter efficiency of integration increased in a linear fashion for nearly 180 minutes (Fig. 5). An aliquot allowed to segregate at $25^{\circ}$ for 6 hours yielded $71 \%$ lysogenic cells, representing the maximum efficiency for this mutant. The results indicate that initiation of prophage integration occurs late in the infection, after the cells have begun to divide. Integration is not completed for at least two gencrations, at which time as many as $60-70 \%$ of the genomes have incorporated prophage.

Another temperature - shift experiment tested the ability of phage genomes to integrate after being carried for several bacterial divisions in a nonintegrated intracellular state at $37^{\circ} . \log$ phase cells at $37^{\circ}$ were infected with a multiplicily of $20 L 1$ phage and diluted to $10^{3}$ cells $/ \mathrm{ml}$ in broth containing antiphage serum as before. Here, however, incubation was continued at $37^{\circ}$. Cell concentration was kept constant by serial dilution into serum and broth. At 10-minute intervals, $1-\mathrm{ml}$ samples were removed to $25^{\circ}$ and incubated for an additional 9 hours (9 generations). The percentage of phagecarrying cells was determined at the time of transfer to $25^{\circ}\left(f_{n}\right)$ and at the end of the 9 hours' incubation $\left(f_{\infty}\right)$. After an initial period of segregation, the $f_{0}$ value halved with each 20-minute generation time as expected for simple dilution of nonintegrated phage genomes (Fig. 6). The corresponding $f_{\infty}$

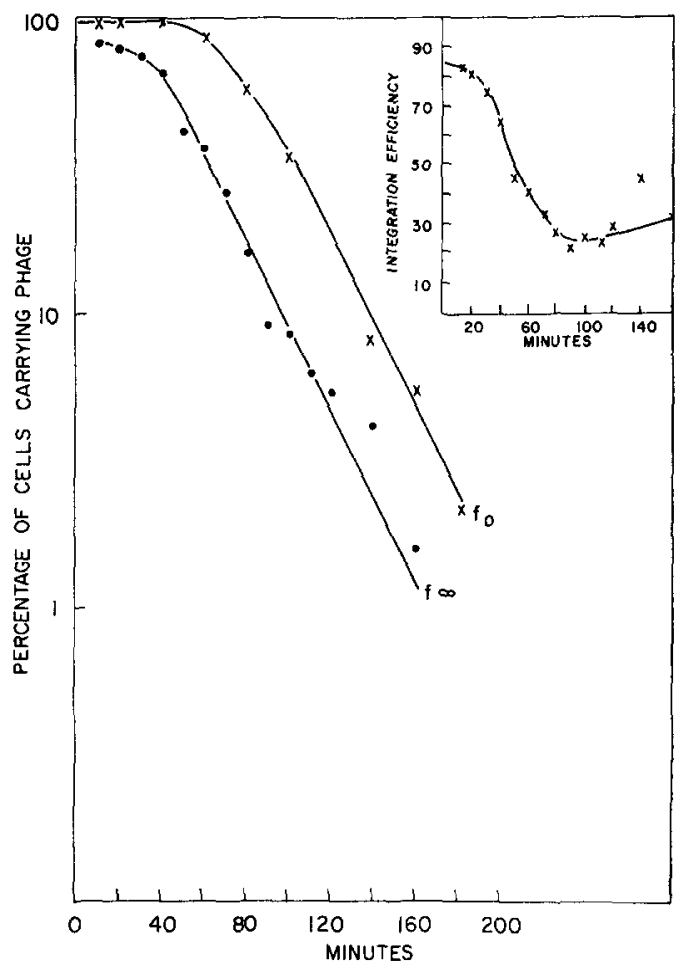

FIG. 6. Integration efficiency of $L 1$ phage at $25^{\circ}$ after prolonged segregation as nonintegrated, intracellular genomes at $37^{\circ} . \times$, per cent phage carriers after segregation at $37^{\circ}$ for various times $\left(f_{0}\right) .0$, per cent phage carriers after transfer to $25^{\circ}$ for an additional 9 hours at each time $\left(f_{\infty}\right)$. Inset: Integration efficiency $=\left(f_{\infty} / f_{0}\right) \times 100$ is shown for a number of time points.

values were lower but parallel to those of $f_{0}$ after approximately 80 minutes. The ratio of $\int_{\infty} / \int_{0}$, which gives the integration efficiency at each time, was high initially when each phage-carrying cell still contained multiple phage genomes, but eventually fell to a constant value of $25-30 \%$ (Fig. 6 , inset), a result which might be expected if only one phage genome were available to lysogenize a binucleate cell containing perhaps 3 or 4 prophage integration sites among its replicating chromosomes. Nonintegrated temperaturesensitive $L 1$ genomes thus maintain their ability to efficiently carry out functions necessary for stable integration, simply by transfer to $25^{\circ}$, as late as 160 minutes after infection.

\section{DISCUSSION}

It has been recognized for some years that the establishment of lysogeny occurs in two 
relatively distinct and independent stages. In phage $\mathrm{P} 22$, the first stage, is under the control of the $c$ region comprised of three genes, $c_{1}, c_{2}$, and $c_{3}$ (Levine, 1957). When these genes function properly, the cells survive as phage carriers. Studies of DNA synthesis have shown that the $c_{1}$ and $c_{2}$ genes work sequentially to affect repression of phage DNA synthesis, preventing vegetative phage development and allowing survival of infected cells (Smith and Levine, 1964, 1965a; Levine and Smith, 1964). The $c_{1}$ gene functions briefly in the 6-10th minute of infection to initiate repression of phage DNA synthesis, the $c_{2}$ gene exerts its effect beginning at about minute 16 , and its action persists indefinitely. Requirement for the $c_{3}$ gene is not absolute; and, consequently, it has been more difficult to study. One might speculate that its effect is to assure a smooth transition between the sequential $c_{1}$ and $c_{2}$ functions.

Lieb (1953b) recognized that establishment of a stable prophage state did not automatically follow the successful repression of phage growth. In fact, prophage attachment could be prevented by appropriate heat treatment of $\lambda$-infected $F$ scher $i$ chia coli. She used the term reduction (after Lwoff, 1953) for this postrepression stage of prophage establishment. A clearer statement of the separation of repression of phage multiplication from incorporation of prophage into the bacterial genome was made by Zichichi and Kellenberger (1963) in their work with the $\lambda b_{n}$ mutant. Experiments with the $L$ mutants of phage P22 further clarify the picture.

For the rest of this discussion we have adopted the term reduction for the initial decision toward cell survival and integration for the later step in which the intracellular phage genome becomes incorporated as prophage. The complete process, terminating in a lysogen, is called the lysogenic response.

The $L$ mutants comprise a single, mutually noncomplementing group which produce turbid plaques and accomplish reduction as efficiently as wild-type phage. They are, however, completely blocked in a function necessary for integration. Thus they cannot complete the lysogenic response. Infected cells become sensitive as a conse- quence of progressive dilution of the nonintegrated, nonreplicating intracellular $I_{i}$ genomes.

Mutant $L$ phage are complemented by $L^{+}$phage to yield stable $L$ lysogens. The $L^{+}$ gene must therefore be acting trans via a diffusible product. Occurrence of temperature-sensitive $L$ mutants makes it unlikely that we are dealing with a group of deletions. The possibility that these are deletions similar to the $b_{2}$ deletion mutant of phage $\lambda$ (Kellenberger, 1961) therefore is ruled out. Phage $\lambda b_{2}$ is deleted in the region of phagebacterial association and camnot integrate except as a second prophage cis to (within) a $b_{2}{ }^{+}$prophage (Campbell, 1965). The map position of the $L$ genc is between $m_{3}$ and $c_{1}$. Prophage undergoes a circular permutation of the vegetative order by separating between these same markers (Smith and Levine, $1965 \mathrm{~b})$. The $m_{3}-c_{1}$ section thus contains the region of phage-bacterial association analogous to the $\lambda b_{2}$ region. If a locus analogous to $L$ exists in $\lambda$ it could well be deleted by the $b_{2}$ lesion, making $\lambda b_{2}$ defective, both functionally and structurally in lysogenizing ability.

Experiments with the temperature-sensitive $L$ mutants have demonstrated that integration is initiated late, at least $80 \mathrm{~min}-$ utes after infection at $25^{\circ}$. This is long after reduction is complete and much of the phage genetic activity is repressed under the influence of the $c_{2}$ gene. This is in seeming contrast to findings with $\lambda$. Integration is irreversibly prevented by temperature treatment $\left(45^{\circ}\right)$ started before minute 15 of the infection. High temperature exposure after minute 15 permits normal anounts of lysogenization (Zichichi and Kellenberger, 1963). It is of course possible that this effect is due to another locus concerned with integration which is not analogous to the P22 $L$ locus.

Prophage integration with phage P'2 appears to be a slow process, occurring at a constant rate for approximately 2 hours at $25^{\circ}$ before leveling off. Luria et al. (1958), in an elegant analysis of pedigrees of phage P22-infected cells, detected cell-carrier states which gave rise to stable lysogens after several generations. These findings are in essential agreement with ours. In keeping with its late action, is the finding that the $L$ 
locus does not irreversibly lose its ability to function after prolonged segregation of phage genomes in a nonintegrated state. Fiven after 8 generations of growth of temperature sensitive $L$ mutant infected cells at the nonpermissive temperature, a shift to $25^{\circ}$ still results in efficient prophage integration.

The specific function of the $L^{+}$locus in integration can only be speculated about at this time. It clearly must be involved in one of the last steps in integration. A study of the defect in phage produced by induction of $L$ mutant lysogens may be important in elucidating the $L$ locus function. This is now under examination and will be the subject of a later publication.

\section{REFERENCES}

Bode, V.C., and $K_{\text {AIser, }} A$. D. (1965). Changes in the structure and activity of $\lambda$ DNA in a superinfected immune bacterium. J. Mol. Biol. 14, $399-417$.

Calef, E. and Licchardello, G. (1960). Recombination experiments on prophage host relationships. Virology 12, 81-103.

Chmprell, A. (1962). Episomes. Advanc. in Genetics, 11, 101-145.

Campbell, A. (1965). The steric effect in lysogenjzation by bacteriophage lambda. II. Chromosomal attachment of the $b_{2}$ mutant. Virology 27 , $340-345$.

Franklin, N. C., Dove, W. F., and Yanofsky, C. (1965). The linear insertion of a prophage into the chromosome of $E$. coli shown by deletion mapping. Biochem. Biophys. Res. Commun. 18, 910923 .

Kellenberg, G., Zichichi, M. L., and Weigle, J. J. (1961). A mutation affecting the I)NA content of bacteriophage lambda and its lysogenizing properties. J. Mol. Biol. 3, 399-408.
Levine, M. (1957). Mutations in the temperate phage P22 and lysogeny in Salmonella. Virology 3, 22-41.

Levine, M., and Curtiss, R. (1961). Genetic fine structure of the $c$ region and the linkage maps of phage P22. Genetics 46, 1573-1580.

Levine, M., and Smith, H. O. (1964). Sequential gene action in the establishment of lysogeny. Science 146, 1581-1582.

Lisi, M. (1953a). The establishment of lysogeny in Escherichia coli. J. Bacteriol. 65, 642-651.

Lieb, M. (1953b). Studies on lysogenization in Escherichia coli. Cold Spring Harbor Symp. Quant. Biol. 18, 71-73.

Lulia, S. E., Fraser, D. K., Adams, J. N., and Burrows, J. W. (1958). Lysogenization, transduction, and genetic recombination in bacteria. Cold Spring Harbor Symp. Quant. Biol. 23, 71-82.

Lwoff, A. (1953). Lysogeny. Bacteriol. Rev. 17, 269-337.

Rothman, J. L. (1965). Transduction studies on the relation between prophage and host chromosome. J. Mol. Biol. 12, 892-912.

Smith, H. O., and Levine, M. (1964). Two sequential repressions of DNA synthesis in the establishment of lysogeny by phage P22 and its mutants. Proc. Natl. Acad. Sci. U.S. 52, 356-363.

Smith, H. O., and Levine, M. (1965a). The synthesis of phage and host DNA in the establishment of lysogeny. Virology 25, 585-590.

Smith, II. O., and Lavine, M. (1965b). Gene order in prophage P22. Virology 27, 229-231.

Young, E. T., and Sinsheimer, R. L. (1964). Novel intra-cellular forms of lambda DNA. $J$. Mol. Biol. 10, 562-564.

Zichichi, M. L., and Kellenberger. G. (1963). Two distinct functions in the lysogenization process: The repression of phage multiplication and the incorporation of the prophage in the bacterial genome. Virology $19,450-460$.

ZiNder, N. D. (1958). Lysogenization and superinfection immunity in Salmonella. Virology $\mathbf{5}$, 291- 326 . 